\title{
Next-day Parathyroid Hormone as a Predictor of Post-thyroidectomy Hypocalcemia
}

\author{
${ }^{1}$ Anish J Cherian, ${ }^{2}$ Pooja Ramakant, ${ }^{3}$ Thomas V Paul, ${ }^{4}$ Deepak T Abraham, ${ }^{5}$ MJ Paul
}

\begin{abstract}
Aim: Total thyroidectomy is significantly complicated by parathyroid dysfunction and hypocalcemia. These aspects impact the decision regarding the timing of discharge and quantum of calcium supplementation required. Therefore, we aimed at evaluating the accuracy of next-day parathyroid hormone (PTH) level as a predictor of post-thyroidectomy hypocalcemia. Secondly, we aimed at establishing our institution's postoperative PTH level, which can accurately predict the development of post-thyroidectomy hypocalcemia to help us ensure the safe and early discharge of patients.
\end{abstract}

Materials and methods: A prospective observational study of 50 continuous patients undergoing thyroidectomy was conducted at a tertiary hospital in South India. Postoperative blood samples were collected for estimation of PTH, calcium, albumin, and phosphorous. The data were collated and results analyzed using Stata I/C 10.1.

Results: A total of $30 \%(15 / 50)$ of the patients had postoperative hypocalcemia (serum calcium $<8 \mathrm{mg} / \mathrm{dL}$ ). Postoperative PTH was low $(<8 \mathrm{pg} / \mathrm{mL})$ in $40 \%(20 / 50)$ of patients. There was a significant association between PTH $<8 \mathrm{pg} / \mathrm{mL}$ and the presence of postoperative hypocalcemia $(p=0.029)$. The area under the receiver operating characteristic (ROC) curve was 0.7 , and a next-day PTH of $<6 \mathrm{pg} / \mathrm{mL}$ showed the highest sensitivity and specificity ( 83 and $60 \%$ respectively) for the development of postoperative hypocalcemia, with a positive predictive value (PPV) and negative predictive value (NPV) of 83 and 60 respectively.

Conclusion: The PTH assessment performed the day after surgery is an acceptable test to predict post-thyroidectomy hypocalcemia; PTH $<6 \mathrm{pg} / \mathrm{mL}$ can be used as our institution's cutoff value. Department protocols for calcium and vitamin D supplementation following total thyroidectomy may be formulated based on the appropriately timed local postoperative PTH value to assist safe and early discharge of patients.

Clinical significance: Discharge protocols for patients undergoing thyroidectomy may be formulated based on the postoperative PTH values, thus enabling safe and early discharge of patients.

Keywords: Calcium, Hypocalcemia, Observational study, Parathyroid hormone, Thyroidectomy.

\footnotetext{
${ }^{1}$ Assistant Professor, ${ }^{2}$ Associate Professor, ${ }^{3-5}$ Professor

1,2,4,5 Department of Endocrine Surgery, Christian Medical College, Vellore, Tamil Nadu, India

${ }^{3}$ Department of Endocrinology, Christian Medical College Vellore, Tamil Nadu, India
}

Corresponding Author: Anish J Cherian, Assistant Professor Department of Endocrine Surgery, Christian Medical College Vellore, Tamil Nadu, India, Phone: +914162282609, e-mail: anish@cmcvellore.ac.in
How to cite this article: Cherian AJ, Ramakant P, Paul TV, Abraham DT, Paul MJ. Next-day Parathyroid Hormone as a Predictor of Post-thyroidectomy Hypocalcemia. World J Endoc Surg 2016;8(3):203-207.

Source of support: Dr MGR Medical University research grant; Fluid research grant - CMC, Vellore.

\section{Conflict of interest: None}

\section{INTRODUCTION}

Total thyroidectomy is a common procedure performed the world over. This procedure, though safe in experienced hands, is still associated with hypocalcemia. The duration of hospital stay following thyroidectomy is also largely dependent on the development of hypocalcemia. Factors that can accurately predict the development of post-thyroidectomy hypocalcemia would aid in early and appropriate initiation of calcium supplements as well as predict the safety of early discharge of patients. Postoperative parathyroid hormone (PTH) lower than a value between 8 and $15 \mathrm{pg} / \mathrm{mL}$ measured intraoperatively or on the same day of surgery has been shown to accurately predict the development of post-thyroidectomy hypocalcemia in various studies. ${ }^{1-5}$ At our institution, we do not use intraoperative PTH testing and the default discharge on 2 nd/3rd postoperative day was restricting efficient patient turnover. In low- to middle-income countries like India, the majority of patients do not want to be discharged on the same day of operation because of perceptions of safety and pain control. One additional day in the hospital does not add a significant cost to the procedure. Additionally, postoperative hemorrhage usually occurs within the first 24 hours of surgery and warrants in-patient observation in the absence of efficient return to hospital mechanisms. ${ }^{6}$ We found that the optimal time for safe discharge of our patients is the day after surgery, if the risk of hypocalcemia can be predicted. This study aimed at evaluating the accuracy of next-day morning PTH as a marker for predicting the development of hypocalcemia and obtaining our institution's cutoff value of PTH that predicts hypocalcemia.

\section{MATERIALS AND METHODS}

A prospective observational study of 50 continuous patients undergoing thyroidectomy between October 1 , 2012, and September 30, 2013, was conducted at a tertiary 
care hospital in South India. All adult patients undergoing thyroidectomy for benign or malignant disorders of the thyroid were included in the study. Patients with renal failure and those with concomitant parathyroid disorders were excluded. All the postoperative blood samples were collected between 5 and $6 \mathrm{am}$. Samples were collected for PTH and albumin only on the 1st postoperative day (next day), while for calcium and phosphorous, samples were collected on all postoperative days until discharge. Blood samples for serum PTH that were collected were sent in ice to the biochemistry lab, where its estimation was performed immediately. Hypocalcemia was defined as corrected calcium $<8.0 \mathrm{mg} / \mathrm{dL}$. On the 2 nd day following the operation, all patients who were asymptomatic for hypocalcemia and in whom the corrected serum calcium was normal were discharged. Patients who did not fit the above criteria were continued to be monitored in the ward for symptoms and signs of hypocalcemia and with daily serum calcium and phosphorous. They were discharged once asymptomatic for hypocalcemia or once the corrected serum calcium showed a stable or rising trend. The biochemical estimations of serum calcium, phosphorous, and albumin were performed using the photometric method (modular P800 automated analyzerRoche), and intact parathormone was estimated by chemiluminescence (Adiva Centaur Centre - Siemens). Our laboratory reference range for serum PTH is between 8 and $74 \mathrm{pg} / \mathrm{mL}$. Statistical analyses were performed using Stata I/C 10.1. The descriptive statistics were performed using mean with standard deviation or frequency with percentages. Chi-square and independent t-tests were used to assess the relationship between postoperative hypocalcemia and postoperative PTH. A significant association was defined as a probability value (p) less than 0.05 . To determine the diagnostic accuracy of nextday PTH levels in predicting the onset of hypocalcemia, we analyzed the receiver operating characteristic (ROC) curve and calculated the area under the curve (AUC) for all the patients. The cutoff concentration of PTH giving the highest accuracy was determined directly from the ROC curve. The specificity, sensitivity, positive predictive value (PPV), and negative predictive value (NPV) of nextday PTH in predicting post-thyroidectomy hypocalcemia were calculated. This study was approved by the institution's review board and ethics committee.

\section{RESULTS}

\section{Clinical Characteristics}

The mean age was $42.5 \pm 14.1$ years, with a range of 18-75 years. There were 13 male and 37 female patients. The operations performed included total thyroidectomy in $36(72 \%)$, total + central compartment clearance in 4 $(8 \%)$, total + neck dissection in $8(16 \%)$, and completion thyroidectomy in $2(4 \%)$ patients. A total of 37 patients (74\%) had a malignant histopathology.

\section{Intraoperative Parathyroid Status}

A total of 37 patients did not require parathyroid autotransplantation during thyroidectomy. Among them, nine patients $(24.3 \%)$ developed hypocalcemia. In 13 patients, parathyroid autotransplantation was performed and 6 patients (46.2\%) developed hypocalcemia. Parathyroid autotransplantation in this cohort was not a risk factor for the development of post-thyroidectomy hypocalcemia $(\mathrm{p}=0.14)$.

\section{Postoperative Investigations}

Postoperative hypocalcemia was present in 15/50 (30\%) patients. Low postoperative PTH $(<8 \mathrm{pg} / \mathrm{mL})$ was present in $20 / 50(40 \%)$ patients. Among them, nine (45\%) had hypocalcemia. The PTH for these nine patients was very low $(<3 \mathrm{pg} / \mathrm{mL})$. The remaining 11 patients were normocalcemic despite low PTH values. A total of 30 patients $(60 \%)$ had normal postoperative PTH levels. Among them, six patients $(20 \%)$ had hypocalcemia. These patients are defined as having a false-negative PTH (patients with normal postoperative PTH, but developing biochemical hypocalcemia). These findings are depicted in Flow Chart 1 . There was a significant association between low postoperative PTH $(<8 \mathrm{pg} / \mathrm{mL})$ and the development of post-thyroidectomy hypocalcemia ( $\mathrm{p}=0.029$ ).

In the postoperative period, as the calcium level decreased, serum phosphorous levels increased, suggesting the presence of hypoparathyroidism. Statistical analysis showed no association between serum phosphorous and serum calcium or with PTH ( $\mathrm{p}=0.14$ and 0.07 respectively).

\section{The ROC Curve}

The AUC was 0.67. A postoperative PTH level of 4.1 to 6 $\mathrm{pg} / \mathrm{mL}$ had a sensitivity of $83 \%$ and specificity of $60 \%$ to predict the development of postoperative hypocalcemia, with PPV of 83 and NPV of 60 (Fig. 1 and Table 1).

Flow Chart 1: Postoperative PTH and calcium values

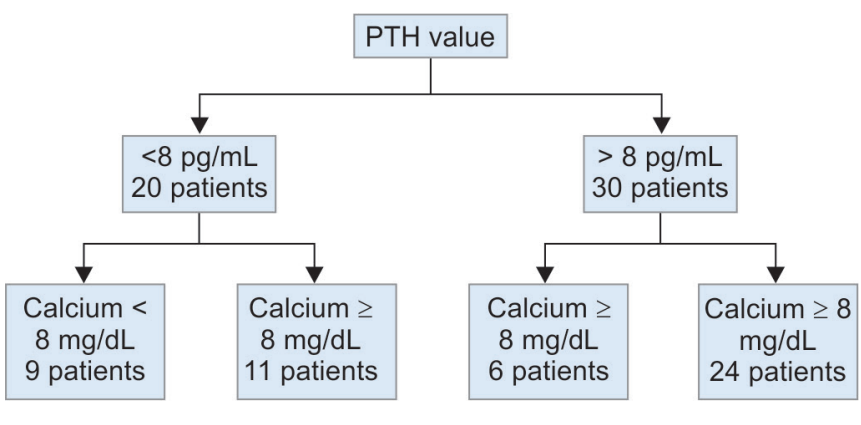


Next-day Parathyroid Hormone as a Predictor of Post-thyroidectomy Hypocalcemia

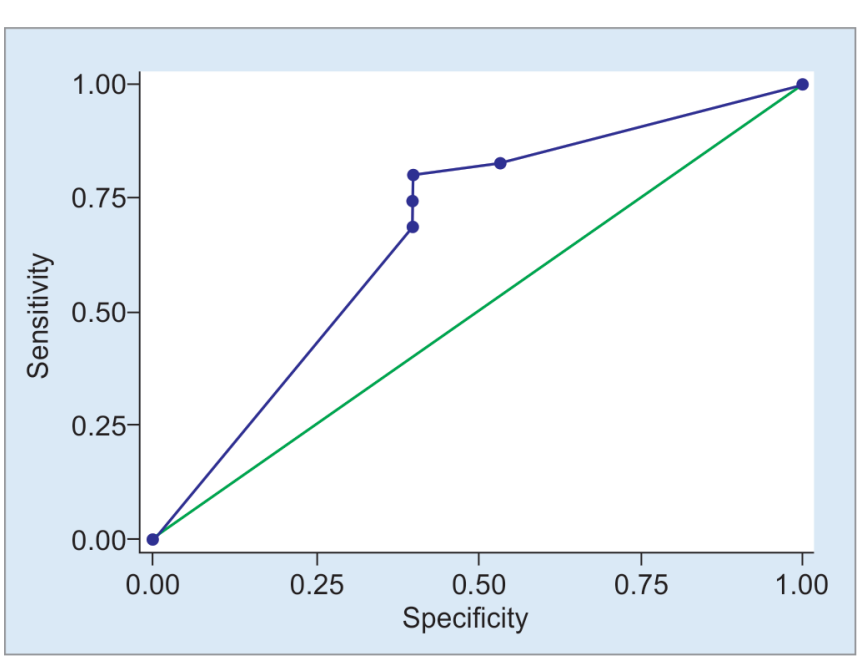

Fig. 1: The ROC curve

\section{DISCUSSION}

Thyroid disorders are common the world over. ${ }^{7,8}$ Many of these can be managed medically. However, there are a large number of patients who require surgical management in the form of thyroidectomy. The indication for surgery includes pressure symptoms, toxicity, retrosternal extension, suspicion of malignancy, malignant goiter, and patient wishes. ${ }^{9-14}$ Our institution being a tertiary center has patients referred for the treatment of thyroid cancer. This is reflected in our department's unpublished audit report on thyroid operations during 2011,2012, and 2013 , which reveal a malignant pathology in $225 / 357$ $(63 \%), 270 / 437(61.78 \%)$, and 292/440 (66.36\%) patients respectively. In this study as well, a higher percentage of malignancy was seen, 37/50 (74\%).

Thyroidectomy is generally a safe procedure, and most patients are discharged 48 hours after surgery. The development of reactionary hemorrhage or hypocalcemia prolongs the duration of hospital stay. Reactionary hemorrhage is a rare occurrence, with an incidence of 0.36 to $4.3 \%$ in the literature. ${ }^{6}$ The majority of hemorrhages present within the first 24 hours of surgery. ${ }^{6,15}$ Monitoring for postoperative hypocalcemia involves observing for symptoms (perioral/extremities paresthesia and numbness) and signs of hypocalcemia (Chvostek's and Trousseau signs) and serial monitoring of serum/ionized calcium. In some patients, there may be a delayed fall in serum calcium (5-7 days) following surgery. If an accurate marker for hypocalcemia can be identified, postoperative monitoring may be limited to 24 hours and may also help to prevent delayed hypocalcemia.

\section{Routine Postoperative Calcium Supplementation}

Many authors advocate routine postoperative supplementation of oral calcium and vitamin $\mathrm{D}$ for patients undergoing total thyroidectomy. ${ }^{16-20}$ They claim the
Table 1: The sensitivity, specificity, PPV, and NPV of various PTH levels

\begin{tabular}{lllll}
\hline $\begin{array}{l}\text { Next-day PTH cutoff } \\
\text { value }(\mathrm{pg} / \mathrm{mL})\end{array}$ & $\begin{array}{l}\text { Sensitivity } \\
(\%)\end{array}$ & $\begin{array}{l}\text { Specificity } \\
(\%)\end{array}$ & PPV & NPV \\
\hline $0-2$ & 100.00 & 0.00 & - & - \\
$2.1-4$ & 85.71 & 46.67 & 78.9 & 58.3 \\
$4.1-6$ & 82.86 & 60.00 & 82.9 & 60 \\
$6.1-8$ & 74.29 & 60.00 & 81.3 & 50 \\
$8.1-10$ & 68.57 & 60.00 & 80 & 45 \\
$10.1-12$ & 62.86 & 60.00 & 78.6 & 40.9 \\
\hline
\end{tabular}

routine calcium and vitamin D supplementation may prevent hypocalcemic symptoms developing in patients with false-negative postoperative PTH. Further, if severe hypocalcemia develops despite routine supplementation, it may be less severe than in patients who were not supplemented and, hence, may be easier to treat. Additionally, multiple measurements of postoperative PTH and calcium may be avoided. On the contrary, in spite of routine supplementation, Singer et $\mathrm{al}^{20}$ have reported development of hypocalcemic symptoms in $7.5 \%$ of their patients and intravenous calcium requirement for severe hypocalcemia in $0.7 \%$. Routine supplementation may cause hypercalcemia with unwanted side effects. None of the above studies except that of Singer et al have mentioned if any of their patients developed adverse effects of calcium supplementation (nausea, abdominal pain, decreased appetite, and constipation), nor do they mention if any patient developed hypercalcemia. Landry et al speculate that routine supplementation may prolong suppression of the parathyroid glands that may be mildly ischemic, and selective supplementation keeping calcium in the low-normal range will prevent unwanted parathyroid suppression. ${ }^{21}$ Routine supplementation can also be a burden to the patients as they will require multiple drug dosing and laboratory testing postoperatively with added cost. Finally, it would be difficult to decide when to taper and stop the supplementation. For the above reasons, we do not routinely supplement patients following thyroid surgery.

\section{Next-day PTH}

A total of 15 patients (30\%) developed postoperative hypocalcemia in this study. Among them, nine patients $(60 \%)$ had low postoperative PTH $(<8 \mathrm{pg} / \mathrm{mL})$. The circulating half-life of PTH is about 3 to 5 minutes. ${ }^{22,23}$ Therefore, its measurement after thyroidectomy should provide an accurate estimation of the remaining parathyroid function. This is in contrast to both ionized and total serum calcium concentrations, which decrease more slowly and do not reach a steady state for several days after a change in parathyroid activity. ${ }^{2}$ The area under the ROC curve of 0.7 in this cohort suggests that 
postoperative PTH is an acceptable test to determine post-thyroidectomy hypocalcemia. The AUC in this study is less compared with other studies probably because of the small number of patients recruited..$^{3-5,24,25}$ Different postoperative PTH cutoff points $(<10$ and $<15 \mathrm{pg} / \mathrm{mL})$ have been described to predict postoperative hypocalcemia. ${ }^{1,3,4,26}$ In the present study, a next-day PTH of 4.1 to $6 \mathrm{pg} / \mathrm{mL}$ showed the highest sensitivity $(83 \%)$ and specificity (60\%). Thus, a next-day PTH value of $6 \mathrm{pg} / \mathrm{mL}$ may be used as our institution's cutoff to decide safe, early discharge of patients.

There are reports of a poor predictive value of postoperative PTH to predict post-thyroidectomy hypocalcemia. Del Rio et $\mathrm{al}^{27}$ found no significant correlation between 1st postoperative day PTH and the onset of hypocalcemia. Lombardi et $\mathrm{al}^{28}$ report a false-negative postoperative PTH rate of $19.4 \%$ (70/360 patients). In our study, a similar falsenegative PTH rate was seen in 20\% (6/30 patients). However, none of the patients with false-negative PTH in the present study required readmission for calcium infusion. They were all early, mild, and transient hypocalcemia, which could be managed with oral supplements alone. Hence, though the development of post-thyroidectomy hypocalcemia is multifactorial, postoperative PTH is an acceptable test to predict significant hypocalcemia of clinical importance.

\section{LIMITATIONS}

For this study to be adequately powered, we required 36 patients who developed hypocalcemia and 36 patients who did not develop hypocalcemia. Hence, this study was underpowered. Following this study, we have been using next-day PTH as a marker for the development of post-thyroidectomy hypocalcemia in our patients routinely and have found it to be a reliable test.

\section{CONCLUSION}

The development of post-thyroidectomy hypocalcemia is multifactorial, hypoparathyroidism being the most common cause. Next-day PTH is an acceptable test to predict post-thyroidectomy hypocalcemia and a PTH $<6 \mathrm{pg} / \mathrm{mL}$ can be used as our institution's cutoff value. Institutional protocols for selective calcium and vitamin D supplementation following total thyroidectomy may be formulated based on the appropriately timed local postoperative PTH value to assist in safe and early discharge of patients.

\section{CLINICAL SIGNIFICANCE}

Discharge protocols for patients undergoing thyroidectomy may be formulated based on the postoperative PTH values, thus enabling safe and early discharge of patients.

\section{REFERENCES}

1. Youngwirth L, Benavidez J, Sippel R, Chen H. Postoperative parathyroid hormone testing decreases symptomatic hypocalcemia and associated emergency room visits after total thyroidectomy. Surgery 2010 Oct;148(4):841-844; discussion 844-846.

2. Sywak MS, Palazzo FF, Yeh M, Wilkinson M, Snook K, Sidhu SB, Delbridge LW. Parathyroid hormone assay predicts hypocalcaemia after total thyroidectomy. ANZ J Surg 2007 Aug;77(8):667-670.

3. Roh JL, Park CI. Intraoperative parathyroid hormone assay for management of patients undergoing total thyroidectomy. Head Neck 2006 Nov;28(11):990-997.

4. Lombardi CP, Raffaelli M, Princi P, Santini S, Boscherini M, De Crea C, Traini E, D'Amore AM, Carrozza C, Zuppi C. Early prediction of postthyroidectomy hypocalcemia by one single iPTH measurement. Surgery 2004 Dec;136(6):1236-1241.

5. Lindblom $P$, Westerdahl J, Bergenfelz A. Low parathyroid hormone levels after thyroid surgery: a feasible predictor of hypocalcemia. Surgery 2002 May;131(5):515-520.

6. Lee HS, Lee BJ, Kim SW, Cha YW, Choi YS, Park YH, Lee KD. Patterns of post-thyroidectomy hemorrhage. Clin Exp Otorhinolaryngol 2009 Jun;2(2):72-77.

7. Vanderpump MPJ. The epidemiology of thyroid disease. $\mathrm{Br}$ Med Bull 2011;99:39-51.

8. Unnikrishnan AG, Menon UV. Thyroid disorders in India: an epidemiological perspective. Indian J Endocrinol Metab 2011 Jul;15(Suppl 2):78S-81S.

9. Chen AY, Bernet VJ, Carty SE, Davies TF, Ganly I, Inabnet WB, Shaha AR. American Thyroid Association statement on optimal surgical management of goiter. Thyroid 2014 Feb;24(2):181-189.

10. Bhargav PRK, Shekhar S. Surgical indications for goiter with background Hashimoto's thyroiditis: institutional experience. Indian J Surg 2011 Dec;73(6):414-448.

11. Stathopoulos P, Gangidi S, Kotrotsos G, Cunliffe D. Graves' disease: a review of surgical indications, management, and complications in a cohort of 59 patients. Int J Oral Maxillofac Surg 2015 Jun;44(6):713-717.

12. Accetta P, Accetta I, Accetta AC, Araújo MS de, Accetta R, Campos KB. Total thyroidectomy for benign thyroid diseases. Rev Col Bras Cir 2011 Aug;38(4):223-226.

13. Gough IR, Wilkinson D. Total thyroidectomy for management of thyroid disease. World J Surg 2000 Aug;24(8):962-965.

14. Stang MT, Armstrong MJ, Ogilvie JB, Yip L, McCoy KL, Faber CN, Carty SE. Positional dyspnea and tracheal compression as indications for goiter resection. Arch Surg 2012 Jul;147(7):621-626.

15. Nambu J, Sugino K, Oishi K, Yano M, Nishihara M, Dohi K. Characteristics of postoperative bleeding after neck surgery. Surg Sci 2013 Mar;4(3):192-195.

16. Roh JL, Park CI. Routine oral calcium and vitamin D supplements for prevention of hypocalcemia after total thyroidectomy. Am J Surg 2006 Nov;192(5):675-678.

17. Sanabria A, Dominguez LC, Vega V, Osorio C, Duarte D. Routine postoperative administration of vitamin $\mathrm{D}$ and calcium after total thyroidectomy: a meta-analysis. Int J Surg 2011 Jan;9(1):46-51.

18. El-Shinawi M, Nada M, Youssef T, Fakhry E, Raslan S, ElAnwar A, El-Gohry H. Oral calcium and vitamin D supplementation after total thyroidectomy. Thyroid Res Pract 2014 Sep;11(3):98-102. 
19. Tolone S, Roberto R, Genio G del, Brusciano L, Parmeggiani D, Amoroso V, Casalino G, Verde I, Bosco A, D'Alessandro A, et al. The impact of age and oral calcium and vitamin $\mathrm{D}$ supplements on postoperative hypocalcemia after total thyroidectomy: a prospective study. BMC Surg 2013 Oct 8;13 (Suppl 2):S11.

20. Singer MC, Bhakta D, Seybt MW, Terris DJ. Calcium management after thyroidectomy: a simple and cost-effective method. Otolaryngol Head Neck Surg 2012 Mar;146(3):362-365.

21. Landry CS, Grubbs EG, Hernandez M, Hu MI, Hansen MO, Lee JE, Perrier ND. Predictable criteria for selective, rather than routine, calcium supplementation following thyroidectomy. Arch Surg 2012 Apr 1;147(4):338-344.

22. Leiker AJ, Yen TWF, Eastwood DC, Doffek KM, Szabo A, Evans DB, Wang TS. Factors that influence parathyroid hormone half-life: determining if new intraoperative criteria are needed. JAMA Surg 2013 Jul;148(7):602-606.

23. Calò PG, Pisano G, Loi G, Medas F, Barca L, Atzeni M, Nicolosi A. Intraoperative parathyroid hormone assay during focused parathyroidectomy: the importance of 20 minutes measurement. BMC Surg 2013 Sep 18;13(1):36.
24. Payne RJ, Hier MP, Tamilia M, Mac Namara E, Young J, Black MJ. Same-day discharge after total thyroidectomy: the value of 6-hour serum parathyroid hormone and calcium levels. Head Neck 2005 Jan;27(1):1-7.

25. Di Fabio F, Casella C, Bugari G, Iacobello C, Salerni B. Identification of patients at low risk for thyroidectomy-related hypocalcemia by intraoperative quick PTH. World J Surg 2006 Aug;30(8):1428-1433.

26. Cote V, Sands N, Hier MP, Black MJ, Tamilia M, MacNamara E, Zhang X, Payne RJ. Cost savings associated with postthyroidectomy parathyroid hormone levels. Otolaryngol Head Neck Surg 2008 Feb;138(2):204-208.

27. Del Rio P, Arcuri MF, Ferreri G, Sommaruga L, Sianesi M. The utility of serum PTH assessment 24 hours after total thyroidectomy. Otolaryngol Head Neck Surg 2005 Apr;132(4): 584-586.

28. Lombardi CP, Raffaelli M, Princi P, Dobrinja C, Carrozza C, Di Stasio E, D'Amore A, Zuppi C, Bellantone R. Parathyroid hormone levels 4 hours after surgery do not accurately predict post-thyroidectomy hypocalcemia. Surgery 2006 Dec;140(6):1016-1023. 